\section{Oyinlade OA}

Olowu AO

Ogunlesi TA

DOI:http://dx.doi.org/10.4314/njp.v40i2,5

Accepted: 1st September 2012

Oyinlade OA ( $\square)$

Department of Paediatrics,

Federal Medical Centre,

Ido-Ekiti, Nigeria.

Email: ladealex2005@yahoo.com

Olowu AO, Ogunlesi TA

Department of Paediatrics, Olabisi Onabanjo University Teaching

Hospital, Sagamu, Nigeria.

\title{
Relationship between anthropometric parameters and the location of apex beat in children
}

\begin{abstract}
Background: Childhood growth is characterized by changes in anthropometric parameters. The location of the apex beat may be similarly influenced by growth.

Objectives: The objective of this study was to determine any relationship between the location of the apex beat and anthropometric parameters.

Subjects and Methods: This crosssectional survey was carried out in Sagamu, Nigeria. Apparently healthy children were randomly selected for the study. Apex beat location in the intercostal space was determined and distance from the midline was recorded. Weight and length/height were also recorded while Body Mass Index (BMI) and Body Surface Area (BSA) were calculated.
\end{abstract}

Results: A total of 237 children aged 12 hours to 10 years were sur- veyed. The mean distance of the apex beat from the midline from birth to 10 years ranged from $2.3 \mathrm{~cm}$ to $6.4 \mathrm{~cm}$. The mean distance of apex beat from the midline increased progressively with weight, height, chest circumference and BSA but not with BMI. Strong correlations were observed between distance of apex beat from the midline and weight $(\mathrm{r}=0.850, \mathrm{p}<$ $0.001)$; height $(\mathrm{r}=0.867, \mathrm{p}<$ $0.001)$; chest circumference $(\mathrm{r}=$ $0.833, \mathrm{p}<0.001)$; BSA $(\mathrm{r}=0.862$, $\mathrm{p}<0.001)$ but not with Body Mass Index $(\mathrm{r}=0.019, \mathrm{p}=0.774)$.

Conclusion: The location of the apex beat in children was strongly influenced by growth as suggested by anthropometric parameters.

Key words: Anthropometry, apex beat, children, mid-clavicular line, nipple line

\section{Introduction}

Over the years, many cardiac diseases in children, both congenital and acquired, have been described in many populations. In Nigeria and most parts of the developing world, congenital heart diseases account for $80-90 \%$ of patients attending most paediatric cardiology clinics, while the acquired variety is responsible for the remaining 10-20\%. ${ }^{1}$ Many of these diseases result in enlargement of the heart with consequent displacement of the apex beat. Therefore, clinical assessment of the location of the apex beat is helpful in detecting likely cardiac diseases particularly in resource-constrained parts of the world where diagnostic imaging is scarce. Unfortunately, literature on the location of the apex beat among healthy children is sparse in the developing world. Till date, only one study carried out among Jamaican children close to three decades ago $^{2}$ described the location of the apex beat in childhood particularly with respect to age. Further, it may be interesting to know how the location of the apex beat changes with growth parameters. in terms of specific parameters like the weight, height and body mass index (BMI). Therefore, as the child grows, these anthropometric parameters also change in specific patterns referred to as somatic growth. In addition to this, visceral growth takes place in specific organs of the body which also increase in size as the total body size increases. For example, renal sizes have been demonstrated to have a strong relationship with anthropometric parameters in a study of renal sizes among Nigerian children. ${ }^{3}$ Therefore, it may not be out of place to expect similar changes in cardiac size with respect to increasing age. In addition, it would also be interesting to relate the location of the apex to growth parameters irrespective of age. Thus, this study was carried out to determine the relationship between apex beat location and anthropometric parameters such as weight, height, body mass index (BMI), body surface area (BSA) and chest circumference among children. 


\section{Methods}

This was a cross sectional study carried out on apparently healthy Nigerian children between December 2009 and April, 2010. The study was conducted in Sagamu, Ogun State; a town located within the Yoruba cultural region of the southwestern Nigeria. Institutional ethical approval was obtained from the Scientific and Ethical Review Committee of the Olabisi Onabanjo University Teaching Hospital, Sagamu and informed consent was also obtained from the parents and guardians of selected children.

Sample size: A previous study ${ }^{2}$ reported the mean apex beat distances from the midline in different age groups of children from birth to ten years. Assuming a margin of error of $5 \%$ of the mean for each age group, the sample that would be necessary to study at $5 \%$ level of significance (95\% confidence interval) was calculated from the formula: ${ }^{4} \mathrm{~N}=\left(\boldsymbol{\sigma}^{2}\left[\mathrm{Z}_{\alpha / 2}\right]^{2}\right) / \varepsilon^{2}$ where $\boldsymbol{\sigma}$ is the assumed standard deviation, $Z \alpha / 2$ represents Type -1 Error while $\varepsilon$ is the margin of error (5\% for each age group). The total calculated sample size was 237 (Table 1).

\begin{tabular}{|c|c|c|c|c|c|}
\hline Age Group & Mean & $\sigma$ & $\mathrm{Z}_{\alpha / 2}$ & $\varepsilon$ & Sample size \\
\hline Neonates & 2.8 & 0.4 & 1.96 & 0.19 & 17 \\
\hline$\leq 1 \mathrm{yr}$ & 3.8 & 0.4 & 1.96 & 0.14 & 31 \\
\hline$>1 \mathrm{yr}-\leq 2 \mathrm{yrs}$ & 4.1 & 0.7 & 1.96 & 0.21 & 43 \\
\hline$>2 \mathrm{yrs}-\leq 3 \mathrm{yrs}$ & 4.7 & 0.3 & 1.96 & 0.24 & 06 \\
\hline$>3 \mathrm{yrs}-\leq 4 \mathrm{yrs}$ & 4.6 & 0.4 & 1.96 & 0.23 & 12 \\
\hline$>4 \mathrm{yrs}-\leq 5 \mathrm{yrs}$ & 5.0 & 0.8 & 1.96 & 0.25 & 39 \\
\hline$>5 \mathrm{yrs}-\leq 6 \mathrm{yrs}$ & 5.1 & 0.5 & 1.96 & 0.26 & 14 \\
\hline$>6 \mathrm{yrs}-\leq 7 \mathrm{yrs}$ & 5.2 & 0.7 & 1.96 & 0.26 & 28 \\
\hline$>7 \mathrm{yrs}-\leq 8 \mathrm{yrs}$ & 5.4 & 0.6 & 1.96 & 0.27 & 19 \\
\hline$>8 \mathrm{yrs}-\leq 9 \mathrm{yrs}$ & 5.5 & 0.5 & 1.96 & 0.28 & 12 \\
\hline $\begin{array}{c}>9 \mathrm{yrs}-\leq 10 \mathrm{yrs} \\
\text { Total }\end{array}$ & 5.7 & 0.6 & 1.96 & 0.29 & $\begin{array}{l}16 \\
237\end{array}$ \\
\hline
\end{tabular}

Sampling method: The neonates and infants were recruited from the maternity unit and Immunization Clinic of the Olabisi Onabanjo University Teaching Hospital, Sagamu. Children aged between one and five years were recruited from day care centres and nursery schools while children aged between 6 and 10 years were recruited from primary schools in Sagamu, all of which were randomly selected.

The inclusion criterion was age from birth to 10 years. The newborn babies included were term, products of spontaneous vertex delivery, appropriate for gestational age from 12 hours of age without asphyxia or other forms of critical illness. Physical examinations of subjects were done to exclude cardiac pathology and chronic illnesses. Subjects with displaced trachea, cardiac murmurs, cyanosis or features of chronic debilitating conditions were excluded. Those who satisfied the inclusion criteria were recruited consecutively until the sample size was reached.
Physical Examinationns and Measurements: Before the commencement of the study, two research assistants who were junior resident doctors in the same department with the researcher were trained in the art of the examination according to specified methodology. One research assistant was trained in the art of physical examination and apex beat location and for every ten children the researcher examined, the research assistant examined one child to minimize observer error. The other research assistant assisted in anthropometric measurements and for every ten children the researcher examined, this assistant also examined one to minimize observer error.

For each subject, the location of the apex beat was determined according to standard clinical methods. ${ }^{5}$ The apex beat was determined in the supine position in the newborn babies and infants, in erect position in children aged between one and three years, and in both erect and supine positions in the others. ${ }^{2}$ The location of the apex beat was measured from the midline, nipple line and the mid-clavicular line. The midline was established by joining the central point in the suprasternal fossa to the xiphisternal angle, and the horizontal distance of the apex beat and the nipple were measured from the midline using an inelastic tape. The extreme medial and lateral ends of the clavicle were identified and the corresponding points on the skin marked with ink. The length of the clavicle represented by these points marked on the skin was similarly measured. Half of the clavicular length was taken as corresponding to the mid clavicular line. Horizontal distance of the mid clavicular line was measured from the midline.

In subjects below two years of age, the weight was measured using the KinLee ${ }^{\circledR}$ electronic bassinette weighing scale with accuracy of $0.01 \mathrm{~kg}$ with the subjects naked while in subjects above two years of age, the weight was measured with the Globe ${ }^{\circledR}$ electronic weighing scale with accuracy of $0.1 \mathrm{~kg}$, with the subject standing upright and bare footed on the scale and with only pants on.

Heights were measured in subjects above two years of age using a stadiometer, with the child standing erect and bare footed on the stadiometer. ${ }^{6-8}$ In subjects below two years of age, the recumbent length was measured using an infantometer. Both equipment were calibrated in centimetres and millimetres.

There are two landmarks which can be used for the measurement of chest circumference. It can be measured at the level of the nipple ${ }^{9}$ and at the level of the xiphisternal junction ${ }^{10}$. However, because the level of the nipple may vary among individuals ${ }^{10}$, therefore, the chest circumference was measured in this study at the level of the Xiphisternal junction, using an inelastic measuring tape calibrated in centimeters and millimeters.

From the measured values of weight and height, the body mass index were calculated as follows: ${ }^{11}$

BMI $=$ Weight $(\mathrm{Kg}) /$ Height $(\mathrm{m})^{2}$

The body surface area was obtained using the 
Mosteller's formula: ${ }^{12} \mathrm{BSA}=\sqrt{[}[$ Weight $(\mathrm{Kg}) \times$ Height $(\mathrm{cm})] / \sqrt{ } 3600$. The values of BMI and BSA were recorded to the nearest three decimal places.

The data were analysed with SPSS version 15.0 software using the Students $t$ test, linear regression analysis and the Pearson Correlation (r). P values less than 0.05 were accepted as significant.

\section{Results}

A total of 237 children with ages ranging from 12 hours to 10 years were studied. These consisted of 131 $(55.3 \%)$ males and $106(44.7 \%)$ females $(\mathrm{M}: \mathrm{F}=1: 0.8)$. The mean distance of the apex beat from the midline for each age group is depicted in Table 2 .

Table 2: The mean distance of apex beat from the midline in the supine and erect positions

\begin{tabular}{lccc} 
Age(months) & $\mathrm{N}$ & $\begin{array}{l}\text { Supine } \\
\text { Mean (SD) }\end{array}$ & $\begin{array}{l}\text { Erect } \\
\text { Mean (SD) }\end{array}$ \\
\hline Neonates & 17 & $2.3(0.6)$ & $\mathrm{NC}$ \\
$\leq 1 \mathrm{yr}$ & 31 & $2.7(0.4)$ & $\mathrm{NC}$ \\
$>1 \mathrm{yr}-\leq 2 \mathrm{yrs}$ & 43 & $\mathrm{NC}$ & $3.4(0.6)$ \\
$>$ yrs $-\leq 3 \mathrm{yrs}$ & 06 & $\mathrm{NC}$ & $4.8(1.1)$ \\
$>$ 3yrs $-\leq 4 \mathrm{yrs}$ & 12 & $5.0(1.3)$ & $5.0(1.3)$ \\
$>$ 4yrs $-\leq 5 \mathrm{yrs}$ & 39 & $4.9(1.1)$ & $4.9(1.1)$ \\
$>5 \mathrm{yrs}-\leq 6 \mathrm{yrs}$ & 14 & $5.5(0.7)$ & $5.5(0.8)$ \\
& & & \\
$>6 \mathrm{yrs}-\leq 7 \mathrm{yrs}$ & 28 & $6.0(0.6)$ & $6.0(0.6)$ \\
$>7 \mathrm{yrs}-\leq 8 \mathrm{yrs}$ & 19 & $6.3(0.6)$ & $6.3(0.7)$ \\
$>8 \mathrm{yrs}-\leq 9 \mathrm{yrs}$ & 12 & $6.7(0.5)$ & $6.7(0.5)$ \\
$>9 \mathrm{yrs}-\leq 10 \mathrm{yrs}$ & 16 & $6.4(0.9)$ & $6.4(0.8)$ \\
\hline
\end{tabular}

NC: Not computed

Relationship between apex beat location and anthropometric parameters

Apex Beat location and Chest Circumference

Figure 1 shows a gradual increase in mean distance of apex beat from the midline with increasing chest circumference.

With respect to correlation, significant correlation occurred only in the 4 to 5 years age group $(r=0.372, p=$ $0.0020)$ and between 7 and 8 years $(r=0.577, p=$ $0.010)$. However, overall correlation from birth to 10 years showed strong and significant correlation between Chest Circumference and distance of apex beat from the midline $(\mathrm{r}=0.833, \mathrm{p}=0.000)$.

\section{Apex beat location and Weight}

Figure 2 shows progressive increase in the mean distance of apex from midline with increasing body weight. Further analysis showed no significant association between body weight and apex beat location in any of the individual age groups. However, overall correlation from neonatal period to 10 years showed significant relationship between body weight and distance of apex beat from the midline $(r=0.746, p=0.000)$.
Fig 1: Graphical relationship of chest circumference and distance of apex beat from the midline

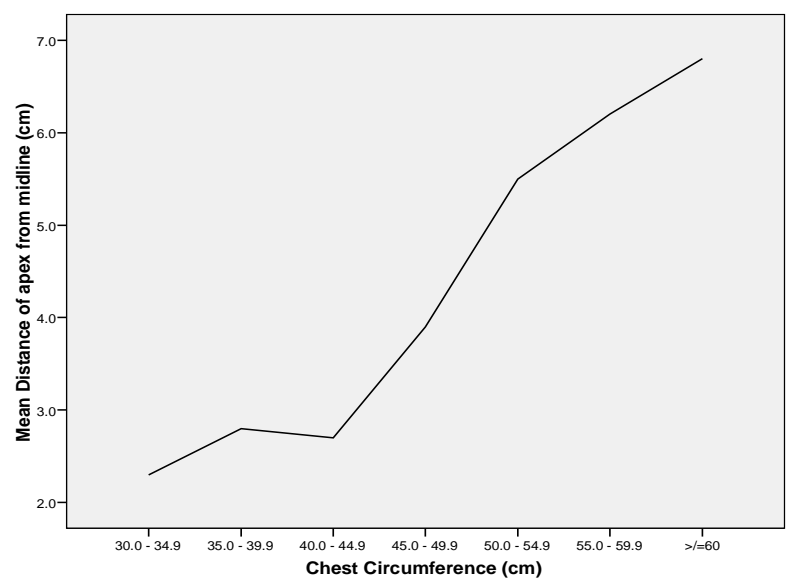

Fig 2: Graphical relationship of weight and mean distance of apex beat from the midline

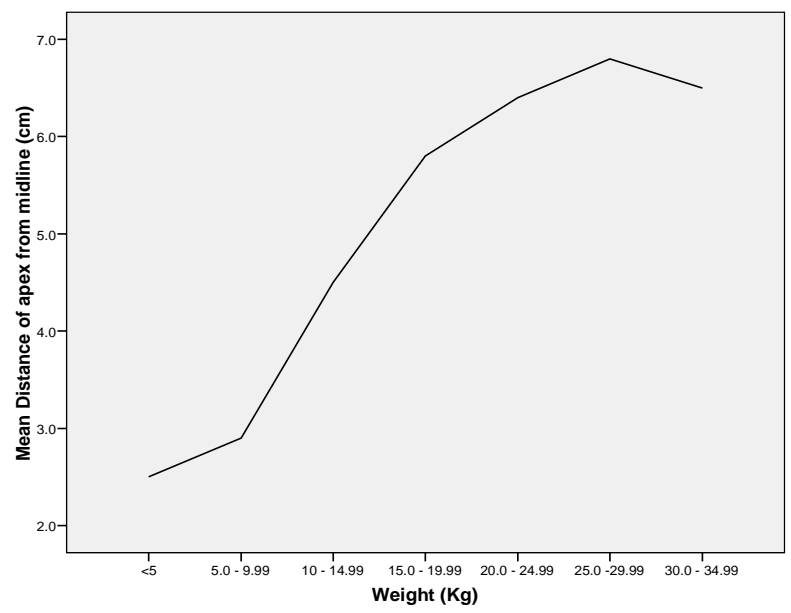

Apex Beat location and height

Figure 3 relates the mean distance of apex from midline to the height. The mean distance of apex beat from the midline increased with increasing height. Strong and significant correlation was found only in age group between 7 and 8 years. However, for all ages together, height was strongly correlated with distance of apex beat from the midline. $(r=0.867, p=0.000)$

Fig 3: Graphical relationship of height and distance of apex beat from the midline

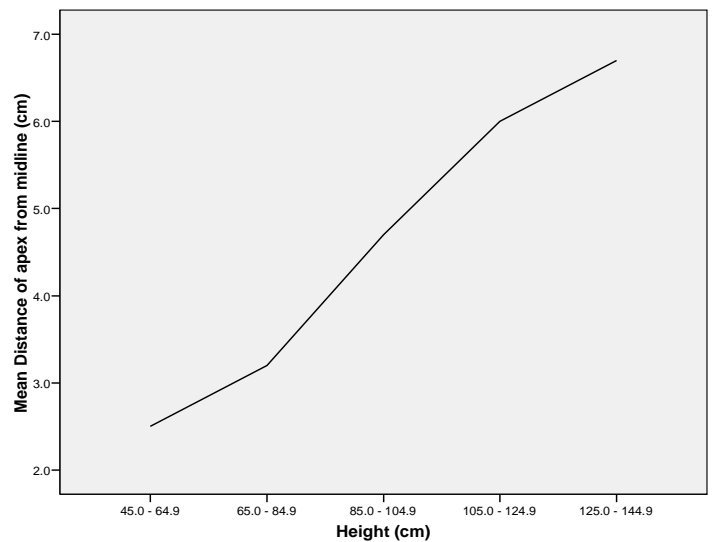


Apex Beat location and Body Mass Index (BMI)

Figure 4 shows the relationship between mean distance of apex from midline and body mass index. There was no linear relationship between body mass index and mean distance of apex beat.

In terms of correlation, significant $\mathrm{p}$ value was found only in age group between 2 and 3 years $(r=0.978, p=$ $0.001)$. However, for all ages together, the correlation between body mass index and distance of apex beat from the midline was weak. $(r=0.019, \mathrm{p}=0.774)$.

Fig 4: Graphical relationship of body mass index and mean apex beat from the midline

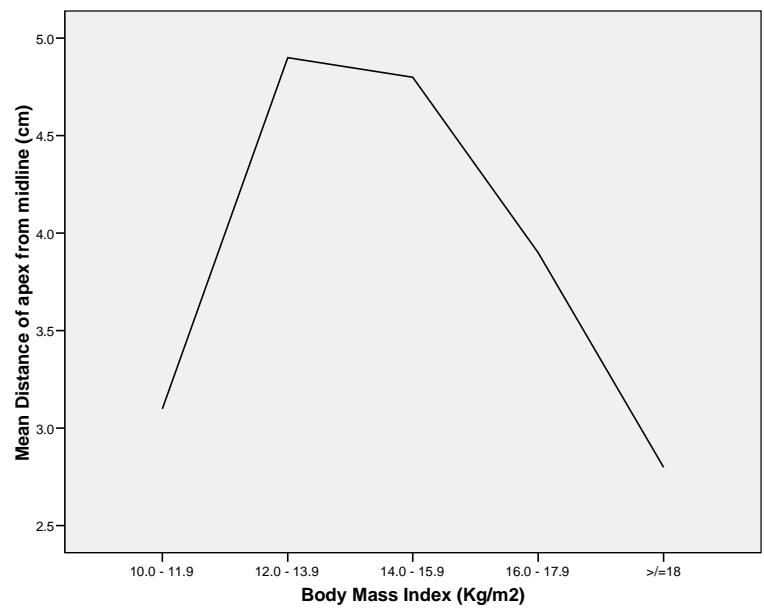

Apex Beat location and body surface area (BSA)

Figure 5 shows the relationship between mean distance of apex from midline and Body Surface Area. A progressive increase in the mean distance of apex beat from the midline with increasing Body Surface Area was noted. On further analysis, significant correlation was observed only in age group between 7 and 8 years $(r=0.743, p=0.041)$. However, for all ages together, there was strong and significant correlation between Body surface area and mean distance of apex beat from the midline $(\mathrm{r}=0.862, \mathrm{p}=0.000)$.

Fig 5: Graphical relationship of body surface area and mean distance of apex beat from the midline

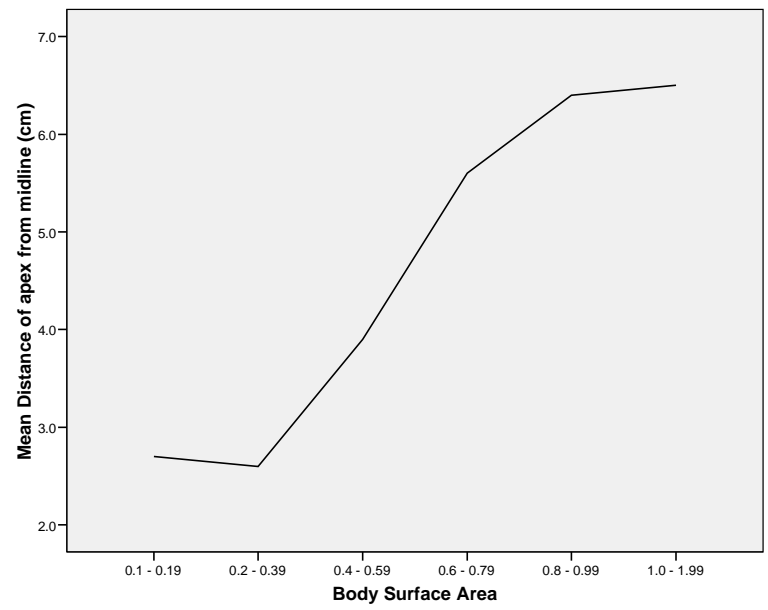

Overall correlation and regression analysis of distance of apex beat from the midline, anthropometric parameters and landmarks on the chest wall (midclavicular line and nipple line)

Table 3 shows the overall correlation and regression analysis of distance of apex beat from the midline,

anthropometric parameters and landmarks on the chest wall (midclavicular line and nipple line). All the anthropometric parameters, midclavicular line and nipple line were strongly and significantly correlated with apex beat except body mass index. The strongest correlation was observed with the height. From these observations, values of the weight, height, body surface area, chest circumference, distance of midclavicular line from midline and distance of nipple line from midline can all be used to predict the distance of apex beat from the midline in children, using the linear regression equation generated with respect to each variable as shown in Table 4. Since BMI shows weak correlation and insignificant $\mathrm{p}$ value, it may not be a reliable factor for predicting apex beat distance from the midline.

Using linear regression equations, predicted distance of the apex beat from the midline can be obtained from values of regression analysis of anthropometric parameters shown on Table 4.

Table 3: Overall correlation and regression analysis of distance of apex beat from the midline, anthropometric parameters and landmarks on the chest wall ( midclavicular line and nipple line )

\begin{tabular}{|c|c|c|c|c|c|}
\hline Parameters & $\begin{array}{l}\text { Pear- } \\
\text { son } \\
(\mathrm{r}) \\
\end{array}$ & $\begin{array}{l}\text { Anova } \\
\text { (F) }\end{array}$ & $\begin{array}{l}\mathrm{P}- \\
\text { values }\end{array}$ & $\begin{array}{l}\text { Con- } \\
\text { stant k }\end{array}$ & $\begin{array}{l}\text { Factor } \\
b\end{array}$ \\
\hline Weight (kg) & 0.850 & $\begin{array}{l}614.20 \\
0\end{array}$ & $0.000 *$ & 1.689 & 0.219 \\
\hline Height $(\mathrm{cm})$ & 0.867 & $\begin{array}{l}709.57 \\
5\end{array}$ & $0.000 *$ & -0.854 & 0.058 \\
\hline BMI (kg / m2) & 0.019 & 0.083 & 0.774 & 4.295 & 0.023 \\
\hline BSA & 0.862 & $\begin{array}{l}681.13 \\
6\end{array}$ & $0.000 *$ & 0.816 & 6.495 \\
\hline $\mathrm{CC}(\mathrm{cm})$ & 0.833 & $\begin{array}{l}534.27 \\
1\end{array}$ & $0.000 *$ & -4.018 & 0.177 \\
\hline $\begin{array}{l}\text { Distance of } \\
\text { MCL } \\
\text { From Midline } \\
\text { (cm) }\end{array}$ & 0.790 & $\begin{array}{l}389.28 \\
1\end{array}$ & $0.000 *$ & -1.263 & 1.135 \\
\hline $\begin{array}{l}\text { Distance Of } \\
\text { NL From } \\
\text { Midline }(\mathrm{cm})\end{array}$ & 0.803 & $\begin{array}{l}427.51 \\
6 \\
\end{array}$ & $0.000 *$ & -2.526 & 1.297 \\
\hline
\end{tabular}

BMI: Body Mass Index; BSA: Body Surface Area; CC: Chest Circumference;

MCL: Mid-clavicular line; NL: Nipple line

Transition of apex beat location from $4^{\text {th }}$ left intercostal space to $5^{\text {th }}$ left intercostal space in relation to anthropometric parameters

Fifty two subjects had their apex beat located in either the $4^{\text {th }}$ or $5^{\text {th }}$ left intercostal space irrespective of age. Their mean anthropometric parameters were calculated to determine the mean parameters at which transition of the apex beat from the $4^{\text {th }}$ left intercostal space to the $5^{\text {th }}$ 
left intercostal space occurred. Table 5 shows the mean values of anthropometric parameters at which transition of apex beat from $4^{\text {th }}$ left intercostal space to $5^{\text {th }}$ left intercostal space occurred.

Using the mean values and standard deviations from table 5 above, the apex beat was more likely in the $5^{\text {th }}$ intercostal space in this study when the weight was $\geq$ $14.1 \pm 1.7 \mathrm{~kg}$ or height $\geq 100.6 \pm 5.1 \mathrm{~cm}$ or $\mathrm{BSA} \geq 0.63 \pm$ $0.05 \mathrm{~m}^{2}$ or chest circumference $\geq 50.9 \pm 2.1 \mathrm{~cm}$. Below these values, it was more likely in the $4^{\text {th }}$ intercostal space.

Table 4: Linear regression equations relating the location of the apex beat to anthropometric parameters.

\begin{tabular}{ll} 
Parameters & $\begin{array}{l}\text { Linear Regression Equation to } \\
\text { determine the location of apex beat } \\
\text { from the midline }\end{array}$ \\
\hline Weight & $0.2 \times$ weight $(\mathrm{kg})+1.7$ \\
Height & $0.1 \times$ Height $(\mathrm{cm})-0.9$ \\
Body Surface Area & $6.5 \times \mathrm{BSA}\left(\mathrm{m}^{2}\right)+0.8$ \\
Chest circumference & $0.2 \times \mathrm{CC}(\mathrm{cm})-4.0$ \\
Mid-clavicular line & $1.1 \times \mathrm{MCL}(\mathrm{cm})-1.3$ \\
Nipple line & $1.3 \times \mathrm{NL}(\mathrm{cm})-2.5$ \\
\hline
\end{tabular}

\begin{tabular}{|c|c|c|c|c|c|}
\hline \multicolumn{6}{|c|}{$\begin{array}{l}\text { Table 5: Transition of apex beat from } 4^{\text {th }} \text { left intercostal space } \\
\text { to } 5^{\text {th }} \text { left inercostal space in relation to anthropometric pa- } \\
\text { rameters }\end{array}$} \\
\hline Parameters & $\mathrm{N}$ & Minimum & Maximum & Mean & SD \\
\hline Weight $(\mathrm{kg})$ & 52 & 11.10 & 20.10 & 14.059 & 1.706 \\
\hline Height $(\mathrm{cm})$ & 52 & 90.70 & 117.00 & $\begin{array}{l}100.60 \\
5\end{array}$ & 5.076 \\
\hline $\begin{array}{l}\mathrm{BMI}(\mathrm{Kg} / \\
\mathrm{m} 2)\end{array}$ & 52 & 10.743 & 16.237 & 13.865 & 0.981 \\
\hline $\mathrm{BSA}\left(\mathrm{M}^{2}\right)$ & 52 & 0.529 & 0.808 & 0.626 & 0.051 \\
\hline $\mathrm{CC}(\mathrm{cm})$ & 52 & 45.000 & 55.500 & 50.909 & 2.059 \\
\hline
\end{tabular}

BMI: Body Mass Index; BSA: Body Surface Area; CC: Chest Circumference

\section{Discussion}

The present study showed that irrespective of the age, values of anthropometric parameters ( weight, height, chest circumference and body surface area ) can be used to predict the position of apex beat in the intercostal space. When the weight was $\geq 14.1 \pm 1.7 \mathrm{~kg}$ or height $\geq$ $100.6 \pm 5.1 \mathrm{~cm}$ or Body Surface Area $\geq 0.6 \pm 0.05 \mathrm{~m}^{2}$ or chest circumference $\geq 50.9 \pm 2.1 \mathrm{~cm}$, the apex beat was more likely in the $5^{\text {th }}$ left intercostal space. Below these values, it was more likely in the $4^{\text {th }}$ left intercostal space. However, values of Body Mass Index were not reliable in predicting apex beat location. This is not surprising since there was no linear relationship between Body Mass index and distance of apex beat from the midline.

The mean apex beat distance from the midline in this study increased with increasing weight, height, Body Surface Area and chest circumference while all the four anthropometric parameters also had strong overall correlation with mean distance of apex beat from the midline. This was not so surprising as the size of the heart in the thoracic cage is expected to increase with increasing weight, height, body surface area and chest circumference. As the heart physiologically enlarges in the thoracic cage proportionately with body size during growth, the apex of the heart is expected to be carried further away from the midline, thereby resulting in increasing apex beat distance from the midline. Using linear regression equations, values of these anthropometric parameters could be used to predict the distance of apex beat from the midline.

Findings of direct correlation between distance of the apex beat and the chest circumference in the 7 to 8 year age-group in this study was similar to earlier findings among Jamaican children aged 7 to 9 years. However, in the Jamaican study, no significant correlation was found in the younger age groups whereas, in this study, significant correlation was found in the 4 to 5 year agegroup. ${ }^{2}$ The reason for this difference is unclear but this may be due to the differences in the sample size studied.

A relatively stronger correlation was found in the relationship between nipple line and distance of apex beat from the midline compared to that of the midclavicular line. It was not clear while the nipple line correlated with apex beat stronger than the midclavicular line in this study. This could be due to possible genetic differences in clavicular lengths and the spacing of the nipples in subjects studied. Changes in socioeconomic factors which could have impacted on growth rates of children over the years could also be contributory, more so that reports have shown that children worldwide have become bigger and taller. ${ }^{13}$ The present study was done in Nigeria while the comparative study was done over three decades ago in Jamaican children with some of the subjects being Chinese and Indian descent. ${ }^{2}$

\section{Conclusion}

The findings in this study has established local peculiarities in the location of apex beat as well as the relationship of apex beat location with landmarks on the anterior chest wall and anthropometric data. These findings are expected to be useful in clinical practice and research particularly with respect to the prediction of the location of the apex beat from the midline using anthropometric parameters. A multicentre study on apex beat location in normal children is highly desirable to validate the findings in this present study.

Conflict of interest : None

Funding : None

\section{Acknowledgement}

The efforts of Drs Adekoya O.A and Ayeni V.A of department of paediatrics, O.O.U.T.H Sagamu are well appreciated. 
References

1. Olowu AO. The burden of Heart Diseases in Children: Any hope for the Nigerian child? $39^{\text {th }}$ Olabisi Onabanjo University Inaugural lecture. Olabisi Onabanjo University Press. 2006; 1-18

2. Antia AU, Maxwell SR, Gough A, Ayeni O. Position of the apex beat in Childhood. Arch Dis Child 1978; 53: 585-9.

3. Adekanmbi AF, Toyobo O, Ogunlesi TA, Fetuga MB. Correlation of anthropometric measurements with renal sizes in Nigerian children: a preliminary report. $\mathrm{Nig}$ Med Pract 2011; 59: 74 - 82.

4. Lemeshow S, Hosmer Jr DW, Klar J, Lwanga SK. Sample size for case control studies. In: Adequacy of sample size in health studies. New York: John Wiley \& Sons (on behalf of World Health Organisation), 1990: 16-20.

5. Swash M. The Cardiovascular System. In: Hutchison's Clinical Methods. 20 $0^{\text {th }}$ Edition.1996; 16673.
6. Obidike EK. Measurements. In: Essentials of Clinical Methods in Paediatrics. Institute for developmental studies, University of Nigeria, Enugu. 2004; 109-115.

7. Tanner JM, Whitehouse RH, Takaishi M. Standards from birth to maturity for height, weight, height velocity, weight velocity, in British children. Arch Dis Child 1966; 41: 454-71 and 613-35

8. Ogunkunle OO, Odutola AO, Orimadegun AE. Pattern of Blood pressure in apparently healthy Nigerian Children aged 1-5 years. Nig J Paed 2007; 34: 14-23.

9. Thangadorai C, Ravikumar T. Physical Examination and Clinical Skill Development. In: Parathasarathy A, ed. IAP Textbook of Paediatrics, $3^{\text {rd }}$ Edition. Jaypee Brothers Medical Publishers, New Delhi, India. 2006; 24-33.
10. Mukherjee DK. Growth and Development. In: Parthasarathy A, Menon PSN, Nair MKC, Bhave S, eds. Partha's Fundamentals of Paediatrics, First Edition. Jaypee Brothers Medical Publishers, New Delhi, India. 2007; 62-95.

11. Robinson TN, Dietz WH. Weight Gain: Overeating to Obesity. In: Rudolph CD, Rudolph AM, eds. Rudolph's Paediatrics, $21^{\text {st }}$ edition. Mc Graw- Hill Medical Publishing Division, New York, 2003: 47681.

12. Nicholson JF, Pesce MA. Reference range for laboratory tests and procedures. In: Berman RE, Kliegman RM, Jenson HB, eds. Nelson Textbook of Paediatrics, $16^{\text {th }}$ edition. Sauders, 2000: 2181-2.

13. Lobstein T, Baul L, Uauy R. Obesity in children and young people: a crisis in public health. Obes Rev 2004; 5: 4-85. 